\title{
nature
}

3 February 2005 Volume 433 Issue no 7025

\section{Facing reality at NASA}

The US space agency is facing a crisis that neither it nor its political stakeholders seem willing to tackle. Something big has to give, and it shouldn't be science.

S ome will say that scientists overreacted to last week's threatened termination of NASA grants for outer-planets research (see page 447). It was much ado about nothing — the money will be awarded after all. But it shows how jumpy space scientists are these days at any hint that their budget might be raided.

They're right to worry. NASA is heading for deep financial trouble, and no one in Washington appears willing to say so.

NASA scored a victory of sorts in the autumn when the White House and Texas Republican Tom DeLay, the most powerful figure in the House of Representatives, made sure the agency got nearly its full budget request of $\$ 16$ billion. Congress also removed the barriers that prevented NASA managers from using space-science funds to solve other problems within the agency.

But these moves can only temporarily hide the truth - that NASA simply can't afford a vigorous space-science programme, a space station, the space shuttle and a new Moon-Mars astronaut programme, all on $\$ 16$ billion a year. The shuttle costs $\$ 4$ billion a year when things are going smoothly. NASA plans to fly 28 shuttles to the space station between now and 2010 - more than the average of 4.7 launches a year, even though the ageing shuttle is down from four vehicles to three and launch directors will be more cautious than ever. Expect delays and cost overruns: the cost of fixing a few systems after the Columbia accident is $\$ 1.5$ billion and counting. The White House promised that its new "vision" would be paid for by phasing out the shuttle and space station, but that already seems like a pipe-dream.

If NASA is committed to finishing the space station, and the Moon-Mars plan remains a White House priority, that leaves only science to cut. But agency managers won't admit this. The battle over servicing the Hubble telescope is a case in point. Outgoing administrator Sean O'Keefe claimed that his decision last year to ban astronaut repair missions to Hubble was based solely on safety. But a National Academy of Sciences panel and the head of the Columbia accident investigation both say a Hubble mission is not significantly more dangerous than a trip to the space station.

No wonder scientists suspect it's really about money. NASA says that any Hubble servicing option — using astronauts or robots will cost about $\$ 2$ billion. What do they get for this? A November report by the Government Accountability Office revealed that nearly half the estimated price of an astronaut servicing mission is for extending the shuttle's life by three months beyond the planned phase-out in 2010. In other words, NASA would charge its spacescience office for the repair flight, something it never used to do, and had not planned to do before the Moon-Mars plan was announced.

Congress will take up the subject of Hubble servicing in a hearing this week. Politicians in Maryland, the home state of the Space Telescope Science Institute, have already promised to come to the telescope's rescue, and some astronomers hope Congress will simply restore the funds for Hubble servicing if the White House cuts them from the NASA budget as expected.

But that would be no substitute for honesty and realism. If NASA maintains its present course, the shuttle and space station will be a drain on its finances for years, leaving little money for the Moon and Mars. And it will be an even greater tragedy if science, NASA's most forward-looking enterprise, suffers to make up the shortfall.

\section{Turf battles versus German excellence}

\section{Disputes between Germany's states and its federal government need not cripple the country's research priorities.}

W hen Chancellor Gerhard Schröder last month opened Germany's celebrations of Albert Einstein's great achievements in 1905, he expounded at great length the urgency of boosting creativity, innovation and enthusiasm for science. But he failed to mention the fact that an ambitious attempt to boost support for curiosity-driven research in Einstein's country of origin was about to crumble, thanks to political manoeuvring.

The programmes designed last year to create world-class centres in German universities and research institutes may fall victim to the chronic battles for power between federal and regional governments (see page 448). Both sides had agreed to support the programmes, and the money - $€ 390$ million (US\$510 million) per year from 2006 to 2010 - had been set aside. Shamefully, the bickering has led to the programmes being put on ice.

The irony is that the impasse is a result of an attempt to undo the Gordian knot of federalism in Germany by loosening the jealously guarded powers of the regions. The attempt has failed dismally. Forlornly, one can only hope that the politicians will learn that science and other key areas are the ultimate victims of their power games.

At the moment, science is being used as a hostage. With Schröder's praise of science still ringing in their ears, this will seem a cynical tactic to Germany's tens of thousands of highly motivated researchers.

But there may be a productive way forward. Some suspect that the Länder (states) governed by the Christian Democrats begrudge the Social Democrat federal government any political success: they may fear that the extra money for science will begin to bear fruit just before the next federal elections in 2006. But rather than block such success, they should try to get a share of it.

The fairest way would be for all to agree to entrust the DFG, Germany's main science funding agency, with the task of distributing in a transparent and competitive way the extra money in the framework of a new programme of research excellence. There is no lack of ideas about how to spend the extra money efficiently. For example, there are many groups in Germany for whom relatively modest equipment grants would enable competition with top centres overseas.

Investment in a few dozen interdisciplinary training programmes, such as the high-profile graduate school for cellular neuroscience at the University of Leipzig, would improve training and career opportunities for many young researchers and greatly increase Germany's attractiveness for the brightest minds from abroad. 